\title{
COMPLEX MATHEMATICAL MODELS FOR ANALYSIS, EVALUATION AND PREDICTION OF AQUEOUS AND ATMOSPHERIC ENVIRONMENT OF LATVIA
}

\author{
Sharif E. Guseynov ${ }^{1,2}$, Eugene A. Kopytov ${ }^{1}$ \\ Transport and Telecommunication Institute \\ Lomonosov Str.1, Riga, LV-1019, Latvia \\ 1,2 \\ Institute of Mathematical Sciences and Information Technologies, Liepaja University \\ 14 Liela Street, Liepaja, LV-3401, Latvia \\ E-mails: sh.e.guseinov@inbox.lv,kopitov@tsi.lv
}

In present paper the authors consider the complete statements of initial-boundary problems for the modelling of various aspects of aqueous ( 3 models) and atmospheric systems ( 2 models) in Latvia. All the proposed models are described in terms of differential equations theory (using both ordinary differential equations and partial differential equations) and are regarded to be the evolutional models. Two of the three aqueous system models being studied are intended to describe the natural aquatic media ecosystems while the other models are aimed at studying environmental pollution processes.

Keywords: environmental pollution, aqueous and atmospheric ecosystem, mathematical modelling, molecular-kinetic model, multicomponent dynamic model, concentration of harmful substances

\section{Introduction}

Since the second half of the XX century the increasing growth of anthropogenic impact on the environment has led to exacerbation of many ecological problems. Prospects for reducing (full solution is not even discussed) the influence of such ecological problems on human life-sustaining activities are connected with implementation of "sustainable development" concept (for instance, see [1-4] and respective references given in these), the main point of which is to ensure the stable coexistence between mankind and nature, which in its turn requires at least to save and reproduce the resource potential; improving the structure of ecosystem exploitation on the basis of scientific approach and performing an analysis for identifying the objective characteristic of ecological situation in order to take a reasonable (even nonoptimal) solution; improving the level of human health. All these necessary conditions for implementation of "sustainable development" concept require:

- development of models and algorithms for unbiased and adequate evaluation of ecosystems' stability;

- finding out the relationships for dynamics of environmental problems;

- improvement of both models and methods of ecological and economic forecasts;

- studying of the combined effect of the anthropogenic loads influencing the ecosystem at large, etc.

The main toolkit in all these studies is mathematical modelling (for instance, see [1-20] and respective references given in these) and/or simulation (for instance, see [5, 20-25]), as well as analytical and numerical methods for solving the constructed models. Among the mathematical models the special place is taken by qualitative models, which are one of the most efficient tools of system analysis - the main approach to the study of ecological systems at various levels. System analysis (for instance, see [4, 26] and respective references given in these) still remains the only tool, in case if carrying out of large-scale field studies and experiments is encumbered because of technical and economical reasons, or is just impossible.

In the construction of mathematical models (both qualitative and quantitative) it is necessary to take into account existing peculiarities of ecological problems. The reason of the specific character of ecological problems is rooted, firstly, in the utmost uncertainty of problems formulation, and, secondly, in the complexity of problems, when it is required to take into account diverse factors starting from geology factors up to the pollution level of atmospheric air, seas and oceans.

As far as engineering practice is concerned (for instance, see $[1,2,5,22,27,28]$ ), it is known that the error of quantitative assessments and calculations could be as large as hundreds percent. The results obtained in [8] in the study of 2-boxed model for the investigation of metabolic processes in the Baltic Sea clearly show the hypersensitivity of water unit even to insignificant discharge amount of human activity wastes (the results of [29] show a similar hypersensitivity in the Black Sea). Eventually, the goal of using formal methods in environmental design, mathematical modelling and forecasting is a more accurate calculation for the scope of ecological damage, forthcoming financial costs as well as effectiveness evaluation for the applied countermeasures. 
Latvia is one of the most successful European countries in ecological problems solving. In accordance with Environmental Performance Index 2010 (see [30]) Latvia takes $21^{\text {st }}$ place among 163 countries in the world by the purity of the environment. Environmental Performance Index (EPI) is produced by a team of environmental experts at Yale University and Columbia University and ranks countries on their performance across 25 metrics aggregated into ten categories including: environmental health, air quality, water resource management, biodiversity and habitat, forestry, fisheries, agriculture, and climate change.

However, Latvia has serious ecological problems. First of all it is the problem of the Baltic Sea health. Latvia has more than 500 kilometres of beach along the Baltic Sea, which is ranked among the most polluted seas in the world. According to the assessment presented in [31], none of the open basins of the Baltic Sea had an acceptable status. Only a very few coastal areas along the Gulf of Bothnia can be considered healthy. Implementation of special international agreements and cross-border programs as well as various studies and research is the way towards a healthy and sustainable-use of the Baltic Sea.

The second serious problem of the environment of Latvia is air pollution, which is particularly heavy during windless, cloudy weather. The main air pollutants are sulphur dioxide, formaldehyde, phenols, ammonia, and nitrogen oxides (see [32]). The transport and energy sectors are the main sources of air pollutant emissions in Latvia. On average more than $80 \%$ of atmosphere pollution in Europe cities comes from motor transport as result of gas burn out (for instance, see [12] and respective references given in this). The chemical content of exhaust depends on gas type and quality, processing technology, burn out technique inside of motor, its technical condition and the following filtration of exhaust (for instance, see [4, 5]). Improving air quality is one of the main priorities of Latvia's environmental policy (see [33]).

In the present paper a set of continuous qualitative models having the dynamic parameters and aimed at analysis, evaluation and forecast of aqueous systems (reservoirs, lakes and seas) and atmospheric environment in Latvia is proposed. In constructing these mathematical models as research tools classic apparatus of differential equations in partial derivatives as well as apparatus of mathematical physics were used. Below there are listed some of the constructed models.

\section{Models of Aquatic Ecosystem}

\subsection{The qualitative model for determination of pollutant concentration dynamics in the "layered in respect to depth" Baltic Sea at a known velocity of pollutant transfer}

In this subsection a mathematical model is proposed for determination of dynamics of pollutant concentration in the Baltic Sea. For constructing of this model the Baltic Sea was divided into parallel narrow horizontal layers, which were perpendicular to the internal normal in respect to the surface of the sea. Moreover, it was supposed that the velocity of pollutant transfer in each layer was known before. The given assumption, obviously, is a quite strong requirement that reduces the value of the offered model to some extent, since determination of pollutant transfer velocity for any non-homogenous environment, including the Baltic Sea, is considered to be independent and quite tough problem. However, despite the limiting role of the given assumption, the offered mathematical model can be used as a primary model for deeper monitoring of the eco-state of the Baltic Sea. Indeed, if roughly assuming that in each layer for some small period of time the velocity of pollutant transfer is constant (this could be achieved by executing the following procedure: significantly increasing the quantity of divisions into sea layers and at the same time significantly reducing the time for study of the pollutant distribution process), then, by using the offered model, after finding its analytical solution, it is possible to determine the quantity of the transferred pollutant amount in each layer with quite high accuracy. Then there appears a question: what is the limitation of the model if after the abovementioned procedure it becomes possible to determine the dynamics of pollutant concentration with a fairly high degree of accuracy? The answer is simple:

- the ideal accuracy of the solution found is only possible with an infinite increase of the layers number and with an infinite reduction of the time period at which the dynamics of pollutant concentration is investigated;

- sufficient accuracy of the solution found is possible at a very large increase of the layers number and at essential reduction of research time period that demands huge computing resources - on the edge of possibilities of modern supercomputers relevant to the possible maximum volume of RAM, CPU throughput, and maximal number of servers joined into cluster having the outmost parallel computing performance, etc.;

- the model is unstable, i.e. rather quite small changes in initial data can lead to a rather large discrepancy between the solution found and the ideal exact solution, which exists, is unique and unknown and which is intended to be reached. Therefore, it is necessary not just to solve the offered model, but to develop a stable method of its solution, having a regularization (by Tikhonov) property. It should be noted that this issue is relatively easily solved. 
So, by denoting as $D$ the studied three dimensional domain of the Baltic Sea, and as $u(x, y, z ; t)$ the desirable concentration of harmful substance in this domain $D$ at the moment of time $t$, the proposed model implies the following: it is necessary to determine the function $u(\xi, t)$, where $u(\xi, t),(\xi, t) \in D \times[0, T], D \subset \mathbb{R}^{3}$, which satisfies

- the equation

$\frac{\partial u(\xi, t)}{\partial t}=\nabla_{\xi}\left(a(\xi) \cdot \nabla_{\xi} u(\xi, t)\right)+\left\langle\alpha, \nabla_{\xi} u(\xi, t)\right\rangle+\beta \cdot u(\xi, t)+f(\xi, t), \xi \in \operatorname{int}\{D\}, t \in(0, T]$

where

$-D \stackrel{\text { def }}{\equiv}\left\{\xi=(x, y, z) \in \mathbb{R}^{3}: x \in\left[0, l_{1}\right], y \in\left[0, l_{2}\right], z \in\left[l_{3}, 0\right] ; l_{j}>0(j=1,2), l_{3}<0\right\}=\operatorname{int}\{D\} \bigcup \partial D$ is $n$ - layered (in respect to axis $O Z$ ) $3 \mathrm{D}$ parallelepiped domain;

$-z \in\left(z_{i-1}, z_{i}\right), i=\overline{1, n} ; z_{0}=l_{3}, z_{n}=0$;

$-a(\xi) \equiv a_{i}=$ const $>0$ if $z \in\left(z_{i-1}, z_{i}\right), i=\overline{1, n}$;

$-n$ is the number of layered media parallel to the plane $X O Y$ in respect to the vertical axis $O Z$;

$-\alpha=\left(\alpha_{1}, \alpha_{2}, \alpha_{3}\right), \alpha_{j}=$ const $(j=\overline{1,3}) ; \beta=$ const;

- $\langle q, r\rangle$ denotes a scalar product of vectors $q \in \mathbb{R}^{3}$ and $r \in \mathbb{R}^{3}$, a symbol $\nabla_{\eta} Q(\eta, \bullet)$ denotes gradient as to the variable $\eta$ of the scalar function $Q(\eta, \bullet)$;

- int $\{D\}$ and $\partial D$ correspondingly denote internal and boundary points of the restricted three-dimensional domain $D \subset \mathbb{R}^{3}$;

- the initial condition

$\left.u(\xi, t)\right|_{t=0}=u_{0}(\xi), \xi \in D ;$

- the boundary conditions

$\left.\gamma_{j, i-1}^{\{i-1\}} \cdot u(\xi, t)\right|_{z=z_{i+j-2}+\varepsilon_{j}}+\left.\gamma_{j, i}^{\{i-1\}} \cdot \frac{\partial u(\xi, t)}{\partial z}\right|_{z=z_{i+j-2}+\varepsilon_{j}}=u_{j, i-1}(x, y, t) ; i=\overline{1,(n+1)}, j=1,2$,

where

$-(x, y, t) \in\left\{D /\left[l_{3}, 0\right]\right\} \times[0, T]$;

$-\varepsilon_{j}=\left\{\begin{array}{lll}+0 & \text { if } j=1 \\ -0 & \text { if } & j=2\end{array}\right.$

$-\gamma_{j, i}^{\{k\}}=\left\{\begin{array}{lll}\forall \text { const }<0 & \text { if } & (j=1) \wedge(i=k=\overline{0, n}) \\ \forall \text { const }>0 & \text { if } \quad \text { otherwise }\end{array}\right.$

$\left.\theta_{j, i-1}^{\{i-1\}} \cdot u(\xi, t)\right|_{\omega=\omega_{j i}}+\left.\theta_{j, i}^{\{i-1\}} \cdot \frac{\partial u(\xi, t)}{\partial \omega}\right|_{\omega=\omega_{j i}}=\vartheta_{j, i}(\xi / \omega, t) ; i=1,2 ; j=1,2$,

where

$-(y, z, t) \in\left\{D /\left[0, l_{1}\right]\right\} \times[0, T]$;

$-(x, z, t) \in\left\{D /\left[0, l_{2}\right]\right\} \times[0, T]$;

$-\omega=\left\{\begin{array}{lll}x & \text { if } & i=1 \\ y & \text { if } & j=2\end{array}\right.$

$-\theta_{j, i}^{\{k\}}=\left\{\begin{array}{lll}\forall \text { const }<0 & \text { if } & (j=1) \wedge(i=k \in\{0 ; 1\}) ; \\ \forall \text { const }>0 & \text { if } \quad \text { otherwise, }\end{array}\right.$

$-\left\{\omega_{j i}\right\}_{j=1,2}^{i=1,2}=\left(\begin{array}{ll}0+0 & 0+0 \\ l_{1}-0 & l_{2}-0\end{array}\right)$; 
- the consistency conditions

$\left.\gamma_{j, i-1}^{\{i-1\}} \cdot u_{0}(\xi, t)\right|_{z=z_{i+j-2}+\varepsilon_{j}}+\left.\gamma_{j, i}^{\{i-1\}} \cdot \frac{\partial u_{0}(\xi, t)}{\partial z}\right|_{z=z_{i+j-2}+\varepsilon_{j}}=\left.u_{j, i-1}(x, y, t)\right|_{t=0+0} ; i=\overline{1,(n+1)}, j=1,2$

where

$-(x, y, t) \in\left\{D /\left[l_{3}, 0\right]\right\} \times[0, T]$

- the value and meaning of constants $\varepsilon_{j}(i=1,2), \gamma_{j, i}^{\{k\}}(j=1,2 ; i=\overline{0,(n+1)} ; k=\overline{0, n})$ are the same as in case of boundary conditions (1.1.3);

$\left.\theta_{j, i-1}^{\{i-1\}} \cdot u_{0}(\xi, t)\right|_{\omega=\omega_{j i}}+\left.\theta_{j, i}^{\{i-1\}} \cdot \frac{\partial u_{0}(\xi, t)}{\partial \omega}\right|_{\omega=\omega_{j i}}=\left.\vartheta_{j, i}(\xi / \omega, t)\right|_{t=0+0} ; i, j=1,2$,

where

$-(y, z, t) \in\left\{D /\left[0, l_{1}\right]\right\} \times[0, T]$

$-(x, z, t) \in\left\{D /\left[0, l_{2}\right]\right\} \times[0, T]$

- the variable $\omega \in\{x, y\}$, and constants $\theta_{j, i}^{\{k\}}(j=1,2 ; i=\overline{0,2} ; k=0,1),\left\{\omega_{j i}\right\}_{j, i \in\{1,2\}}$ have the same values and meaning as for the boundary conditions (1.1.4);

- the conjugating conditions

$\left\{\begin{array}{l}\left.u(\xi, t)\right|_{z=z_{i}+0}=\left.u(\xi, t)\right|_{z=z_{i}-0},(x, y, t) \in\left\{D /\left[l_{3}, 0\right]\right\} \times[0, T] \\ \left.a_{i} \cdot \frac{\partial u(\xi, t)}{\partial z}\right|_{z=z_{i}+0}=\left.a_{i+1} \cdot \frac{\partial u(\xi, t)}{\partial z}\right|_{z=z_{i}-0},(x, y, t) \in\left\{D /\left[l_{3}, 0\right]\right\} \times[0, T]\end{array}\right.$

for $\forall i=\overline{1,(n-1)}$.

In the mathematical model (1.1.1)-(1.1.7) the initial data are represented by a piecewise-constant function $a(\xi)$; velocity vector $\alpha$; constant $\beta \in \mathbb{R}^{1}$; constants $l_{i}(i=\overline{1,3}), T>0$; functions $f(\xi, t) \in C\{D \times[0, T]\} ; u_{j, i}(x, y, t) \in C^{1,1,2}\left\{\left\{D /\left[l_{3}, 0\right]\right\} \times[0, T]\right\} \quad(i=\overline{0, n} ; j=1,2)$; $\vartheta_{j, 1}(y, z, t) \in C^{1,1,2}\left\{\left\{D /\left[0, l_{1}\right]\right\} \times[0, T]\right\},(j=1,2) ; \vartheta_{j, 2}(y, z, t) \in C^{1,1,2}\left\{\left\{D /\left[0, l_{2}\right]\right\} \times[0, T]\right\},(j=1,2)$; constants $\gamma_{j, i}^{\{k\}}(j=1,2 ; i=\overline{0,(n+1)} ; k=\overline{0, n}) ; \theta_{j, i}^{\{k\}}(j=1,2 ; i=\overline{0,2} ; k=0,1)$.

\subsection{Multi-component dynamic model for determination of the main characteristic for the process of substance circulation (taking circulation of nitrogen as an example) in the near-surface layers of the natural aquatic environments (natural reservoirs, large basins, lakes and seas)}

In this subsection a mathematical model is proposed describing circulation of nitrogen in natural aquatic environments for determination of major characteristics of this process. The constructed model is parametric and is described by a system of partial differential equations. It allows decreasing significantly the uncertainty of parameters of the sophisticated circulation process in the non-homogeneous media, the example of which is the natural aquatic environment in the presence of powerful sources and sinks. Reducing the uncertainty of parameters is carried out in the way of (a) identification of relationships imposed on the parameters, (b) finding of non-trivial special points of the system-model and taking into account the stability preservation conditions in respect to these special points for several structures of the circulation process.

The proposed model is constructed under the following assumptions:

- the average temperature of the studied natural aquatic environment for the whole period of the circulation process study is assumed to be constant; 
- the total amount of nitrogen in the studied aquatic environment can be represented in the form of organic and inorganic nitrogen, where the organic nitrogen in its turn can be represented also in two forms - as animated and unanimated nitrogen;

- the reserve of nitrogen in the studied aquatic environment is replenished (a) by means of molecular nitrogen adoption of the air by some free nitrogen fixing agents and (b) by some types of seaweed;

- processes of nitrogen fixing by phytoplankton and bacterial plankton have linear interdependence (with a known coefficient of linearity);

- mineral nitrogen in the aquatic environment is used only by some types of seaweed and planktons;

- protein substances of plants and animal species formed in the studied aquatic environment, after dying off of the organisms are subjected to mineralization with the assistance of bacteria, moreover, decomposition of such protein substances evolves nitrogen, generally in the form of ammonia;

- in the studied process of circulation there occurs direct denitrification (denitrification is a decomposition of nitrogenous compounds with generation of free nitrogen) as well as circumstantial denitrification (circumstantial denitrification - this is a chemical effect of $\mathrm{NO}_{2}^{-}$, ammonium salts and amino acids with generation of free nitrogen);

- the studied circulation process also includes deammonification (decomposition by microorganisms of nitrogen-containing organic compounds with generation of free nitrogen).

So, the offered parametric model anticipates determination of the vector $u(\xi, t) \stackrel{\text { def }}{\equiv}\left(u_{\text {ph.pl. }}, u_{\text {bac.pl. }}, u_{\text {zoo.pl. }}, u_{\text {inor.nit. }}, u_{\text {or.nit. }}\right)(\xi, t) \in C^{0,1}\{D \bigcup[0, T]\} \quad$ of dynamic variables/functions $u_{\text {ph.pl. }}(\xi, t), u_{\text {bac.pl. }}(\xi, t), u_{\text {zoo.pl. }}(\xi, t), u_{\text {inor.nit. }}(\xi, t)$ and $u_{\text {or.nit. }}(\xi, t)$, where $D \stackrel{\text { def }}{\equiv}\left\{\xi=\left(x_{1}, x_{2}, x_{3}\right): l_{x_{3}} \leq x_{3} \leq 0 ; 0 \leq x_{i} \leq l_{x_{i}}(i=1,2)\right\}$, from the non-linear system

$$
\begin{aligned}
& \int \frac{1}{u_{\text {ph.pl. }}(\xi, t)} \cdot \frac{\partial u_{\text {ph.pl. }}(\xi, t)}{\partial t}=k_{1}(\xi)+k_{2}(\xi) \cdot u_{\text {or.nit. }}(\xi, t)+k_{3}(\xi) \cdot u_{\text {inor.nit. }}(\xi, t)-
\end{aligned}
$$

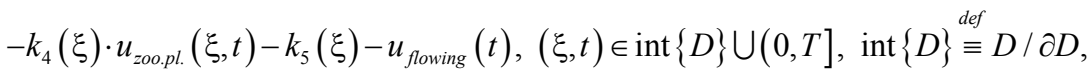

$$
\begin{aligned}
& \frac{1}{u_{\text {bac.pl. }}(\xi, t)} \cdot \frac{u_{\text {bac.pl. }}(\xi, t)}{\partial t}=k_{6}(\xi)-k_{7}(\xi)-k_{8}(\xi)-k_{9}(\xi)-u_{\text {flowing }}(t)+k_{10}(\xi) \cdot u_{\text {or.nit. }}(\xi, t)- \\
& -k_{11}(\xi) \cdot u_{\text {inor.nit. }}(\xi, t)-k_{12}(\xi) \cdot u_{\text {zoo.pl. }}(\xi, t),(\xi, t) \in \operatorname{int}\{D\} \bigcup(0, T] \text {, }
\end{aligned}
$$

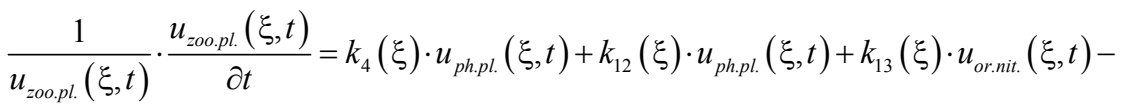

$$
\begin{aligned}
& -k_{14}(\xi)-k_{15}(\xi)-k_{16}(\xi) \cdot u_{\text {flowing }}(t),(\xi, t) \in \operatorname{int}\{D\} \cup(0, T] \text {, } \\
& \frac{1}{u_{\text {inor.nit. }}(\xi, t)} \cdot \frac{u_{\text {inor.nit. }}(\xi, t)}{\partial t}=\frac{c_{1}(\xi)+c_{2}(\xi)}{u_{\text {inor.nit. }}(\xi, t)}+k_{14}(\xi) \cdot \frac{u_{\text {zoo.pl. }}(t)}{u_{\text {inor.nit. }}(\xi, t)}+k_{8}(\xi) \cdot \frac{u_{\text {bac.pl. }}(t)}{u_{\text {inor.nit. }}(\xi, t)}- \\
& -k_{11}(\xi) \cdot u_{\text {bac.pl. }}(\xi, t)-k_{3}(\xi) \cdot u_{\text {ph.pl. }}(\xi, t)-u_{\text {flowing }}(t),(\xi, t) \in \operatorname{int}\{D\} \cup(0, T] \text {, } \\
& \frac{1}{u_{\text {or.nit. }}(\xi, t)} \cdot \frac{u_{\text {or.nit. }}(\xi, t)}{\partial t}=\frac{c_{3}(\xi)+c_{4}(\xi)}{u_{\text {or.nit. }}(\xi, t)}+k_{5}(\xi) \cdot \frac{u_{\text {ph.pl. }}(\xi, t)}{u_{\text {or.nit. }}(\xi, t)}+k_{7}(\xi) \cdot \frac{u_{\text {bac.pl. }}(\xi, t)}{u_{\text {or.nit. }}(\xi, t)}+ \\
& +k_{15}(\xi) \cdot \frac{u_{\text {zoo.pl. }}(\xi, t)}{u_{\text {or.nit. }}(\xi, t)}-k_{10}(\xi) \cdot u_{\text {bac.pl. }}(\xi, t)-k_{2}(\xi) \cdot u_{\text {ph.pl. }}(\xi, t)- \\
& -k_{13}(\xi) \cdot u_{\text {zoo.pl. }}(\xi, t)-k_{17}(\xi)-u_{\text {flowing }}(t),(\xi, t) \in \operatorname{int}\{D\} \bigcup(0, T] \text {, }
\end{aligned}
$$

with initial conditions

$$
\left\{\begin{array}{l}
\left.u_{\text {ph.pl. }}(t)\right|_{t=0}=u_{\text {ph.pl. }}^{0}(\xi) ;\left.u_{\text {bac.pl. }}(t)\right|_{t=0}=u_{\text {bac.pl. }}^{0}(\xi) ;\left.u_{\text {zoo.pl. }}(t)\right|_{t=0}=u_{\text {zoo.pl. }}^{0}(\xi), \quad \xi \in D, \\
\left.u_{\text {inor.nit. }}(t)\right|_{t=0}=u_{\text {inor.nit. }}^{0}(\xi) ;\left.u_{\text {or.nit. }}(t)\right|_{t=0}=u_{\text {or.nit. }}^{0}(\xi), \quad \xi \in D,
\end{array}\right.
$$


where

- functions $u_{\text {ph.pl. }}(\xi, t), u_{\text {bac.pl. }}(\xi, t), u_{\text {zoo.pl. }}(\xi, t), u_{\text {inor.nit. }}(\xi, t)$ and $u_{\text {or.nit. }}(\xi, t)$ denote respectfully the desired amount of phytoplankton, bacterial plankton, zooplankton, inorganic nitrogen and organic nitrogen at the time moment $t \in[0, T]$ at the point $\xi \in D$;

$-T$ is the given finite moment of time, during which the process of substance circulation in the near-surface layers of natural aquatic environments is studied;

$-l_{x_{i}}(i=\overline{1,3}): l_{x_{1}}>0, l_{x_{2}}>0, l_{x_{3}}<0$ are the known boundaries of the considered "parallelepiped" domain of natural aquatic environments;

- the initial functions $u_{\text {ph.pl. }}^{0}(\xi), u_{\text {bac.pl. }}^{0}(\xi), u_{z o o . p l .}^{0}(\xi), u_{\text {inor. nit. }}^{0}(\xi), u_{\text {or.nit. }}^{0}(\xi), \xi \in D$ are a priori known functions, which are continuous in the closed domain $D$;

- the functions $k_{i}(\xi)(i=\overline{1,17}), \xi \in \operatorname{int}\{D\}, c_{i}(\xi)(i=\overline{1,4}), \xi \in \operatorname{int}\{D\}$ and $u_{\text {flowing }}(t), t \in(0, T]$ have the following meaning: $k_{1}(\xi)$ is a coefficient of nitrification of phytoplankton; $k_{2}(\xi)$ is a coefficient of organic nitrogen absorption by phytoplankton; $k_{3}(\xi)$ is a coefficient of mineral nitrogen absorption by phytoplankton; $k_{4}(\xi)$ is a coefficient of phytoplankton consumption by zooplankton; $k_{5}(\xi)$ is a coefficient of emission of organic nitrogen by phytoplankton; $k_{6}(\xi)$ is a coefficient of nitrification of bacterial plankton; $k_{7}(\xi)$ is a coefficient of emission of organic nitrogen by bacterial plankton; $k_{8}(\xi)$ is a coefficient of emission of mineral nitrogen by bacterial plankton; $k_{9}(\xi)$ is a coefficient of denitrification: denitrification - is decomposition of nitrogenous compounds with free nitrogen generation; $k_{10}(\xi)$ is a coefficient of organic nitrogen processing by bacteria; $k_{11}(\xi)$ is a coefficient of mineral nitrogen processing by bacteria; $k_{12}(\xi)$ is a coefficient of bacterial plankton consumption by zooplankton; $k_{13}(\xi)$ is a coefficient of organic nitrogen consumption by zooplankton; $k_{14}(\xi)$ is a coefficient of mineral nitrogen emission by zooplankton; $k_{15}(\xi)$ is a coefficient of organic nitrogen emission by zooplankton; $k_{16}(\xi)$ is a coefficient of zooplankton discharge by higher level predaceous organisms; $k_{17}(\xi)$ is a coefficient of organic nitrogen supply to the lower layer of the considered domain $D$ of natural aquatic environments - the domain of near-surface layers of natural aquatic environments; $c_{1}(t)$ is the inflow of inorganic nitrogen that is equal to the sum of (a) main feeding river sinks, (b) rain surface sinks, (c) inner drainage of mineral fertilizers into the soil, (d) industrial and household discharges, (e) atmospheric precipitations on the water area: water area - is a region of water surface within the set boundaries; $c_{2}(t)$ is the inflow of mineral nitrogen from lower layer silt; $c_{3}(t)$ is the inflow of organic nitrogen from lower layer silt; $c_{4}(t)$ is the inflow of organic nitrogen, equal to the sum of (a) main feeding river flows, (b) atmospheric precipitations on the water area, (c) decaying biomass of phytoplankton and higher level of marine vegetation, (d) emissions of living phytoplankton; $u_{\text {flowing }}(t)$ the power of flow (water circulation; evaporation; etc.).

Remark 1. In the model (1.2.1), (1.2.2) modelling units - are tons of nitrogen per time unit (for instance, per year).

Remark 2. Model (1.2.1), (1.2.2) having any fixed value of spatial variable $\xi=\xi_{f i x} \in D$ becomes a Cauchy problem for the system of ordinary non-linear differential equations, and in this case it is an adequate model for determination of nitrogen circulation in large basins, reservoirs, lakes, ponds, etc.

Remark 3. In the proposed model (1.2.1), (1.2.2) to describe the functional significance of the coefficient $k_{9}(\xi)$, which denoted coefficient of denitrification, it was discussed that the denitrification was a decomposition of nitrogenous compounds with generation of free nitrogen. This definition requires 
a more precise specification. The transition of nitrogen into the gaseous form of nitrates $\left(\mathrm{NO}_{3}^{-} \rightarrow \mathrm{NO}_{2}^{-} \rightarrow \mathrm{N}_{2}\right)$ is called denitrification. Generally speaking, this process in the presence of denitrifying bacteria occurs fairly rapidly only when there are nitrates present, the amount of easily assimilable organic substance is sufficient, as well as anaerobic conditions fulfilled. If the medium together with $\mathrm{NO}_{2}^{-}$contains ammonium salts (or amino acids), the free nitrogen can be generated due to their chemical interaction, namely, $2 \mathrm{KNO}_{2}+\left(\mathrm{NH}_{4}\right) \mathrm{SO}_{4} \rightarrow 2 \mathrm{NH}_{4} \mathrm{NO}_{2}+\mathrm{K}_{2} \mathrm{SO}_{4} ; \mathrm{NH}_{4} \mathrm{NO}_{2} \rightarrow \mathrm{N}_{2}+2 \mathrm{H}_{2} \mathrm{O}$.

This process is called (for instance, see [34]) circumstantial denitrification. Nitrogen losses are also possible in the result of deammonification $\left(\mathrm{NH}_{4} \rightarrow \mathrm{N}_{2}\right)$, and also when generating fugitive nitrogen oxides with the participation of certain amino acids and a variety of unstable nitrogen containing compounds (for instance, see [35]).

As it was mentioned at the beginning of this subsection, in the mathematical model (1.2.1), (1.2.2) we supposed that all the above mentioned processes occurred to a greater or lesser degree, however, in [36], it was shown that the most frequently denitrification was observed in soil, and not in the layers of water.

In the model (1.2.1), (1.2.2) for its simplification all the above mentioned processes are joined into one process called denitrification with one functional coefficient $k_{9}(\xi)$, covering the other possible processes associated with the loss of nitrogen in natural aquatic environments.

\subsection{Model for determination of oxygen condition sensitivity for the Baltic Sea}

In this subsection a mathematical model for determination sensitivity of the oxygen condition in the Baltic Sea is proposed. As it is shown in the work [49], the models sensitivity study anticipates identifying of special features of ecosystem dynamics within the domains bounded by the bifurcation surfaces.

Methods of the sensitivity theory can be used to solve the two types of problems that arise when constructing dynamic multi-component models, including simulation models: (a) at the stage of establishment of the model structure and for binding parameters of the models, which provide concordance during some observations time period; (b) at the stage of studying the model with already established structure for finding irregular special points (that is, "weak places") and stationary points (that is, anaerobic places) of the aquatic ecosystem, as well as for determination of critical values of parameters when modelling toxic effect and anthropogenic eutrophication (eutrophication - is the process of total productivity growth of the water reservoir ecosystem, which includes water masses, bottom deposits and microorganisms living there; eutrophication - is the increase of the level of water primary production owing to the increase in the concentration of biogenic elements there, that is mainly nitrogen and phosphorus).

The model proposed below allows determination of peculiarities of oxygen state dynamics, which cannot be determined by simple enumeration of parameters and/or when using purely statistical methods of parameters estimation.

Moreover, the proposed model allows determining the qualitative properties of the oxygen state dynamics, which significantly reduces the uncertainty in sophisticated interrelations between parameters of dynamics and the environment, allows making adequate high precision forecasts in respect to anthropogenic impact onto the ecosystem and, therefore, reveals trends in the ecosystem state of the sea. Finally, the proposed model can be used as a primary model to determine the condition that leads to anaerobic zones growth strengthening in the Baltic Sea.

As a major restriction of the proposed model there can be noted the impossibility of its usage for the study of the seasonal Baltic Sea ecosystem dynamics in the conditions of aerobic and anaerobic states being below the halocline level.

Remark 4. This model is essentially based on the results of works [7, 24] taking into account the modifying changes from works [37-40], namely, in the Sjoberg anaerobic model non-autonomous system of ordinary differential equations, where in the direct form there are present functions of vertical turbulent mixing, function of lighting and function of temperature, is substituted by autonomous system of equations (such substitution is approved by Floquet and Lyapunov's theorem: the information on the theory of Floquet and Lyapunov, namely, the importance and benefits of Floquet-Lyapunov theorem can be found in books [41, 42] and fundamental monograph [43]; but the widest applications of FloquetLyapunov theorem are given in the book [44]). 
It is required to determine a vector

$u(\xi, t) \stackrel{\text { def }}{\equiv}\left(\bar{u}_{\text {inor.phosph. }}, \underline{u}_{\text {inor.phosph. }}, \bar{u}_{\text {or.phosph. }}, \underline{u}_{\text {or.phosph. }}, \bar{u}_{\text {ph.pl. }}, \underline{u}_{\text {oxyg. }}\right)(t) \in C^{1}[0, T]$

of dynamic variables/functions $\bar{u}_{\text {inor.phosph. }}(t), \underline{u}_{\text {inor.phosph. }}(t), \bar{u}_{\text {or.phosph. }}(t), \underline{u}_{\text {or.phosph. }}(t), \bar{u}_{\text {ph.pl. }}(t)$ and $\underline{u}_{\text {oxyg. }}(t)$ from the system of ordinary non-linear differential equations

$$
\begin{aligned}
& \int \frac{\dot{\bar{u}}_{\text {inor.phosph. }}(t)}{\overline{\bar{u}}_{\text {inor.phosph. }}(t)}=\frac{F_{\text {oxyg. }}^{\text {inor.phosph. }}+F_{\text {ph.pl. }}^{\text {inor.phosp. }}}{\bar{u}_{\text {inor.phosph. }}(t)}+\left(F_{0}+H\right) \cdot c_{1} \cdot \frac{\underline{u}_{\text {inor.phosph. }}(t)}{\bar{u}_{\text {inor.phosph. }}(t)}+ \\
& +k_{1} \cdot T^{\circ} \cdot \frac{\bar{u}_{\text {or.phosph. }}(t)}{\bar{u}_{\text {inor.phosph. }}(t)}-\left(H+F_{\text {oxyg. }}+F_{0}\right) \cdot c_{2}-k_{2}-k_{3} \cdot I \cdot T^{\circ} \cdot \bar{u}_{\text {ph.pl. }}(t), \\
& \frac{\underline{u}_{\text {inor.phosph. }}(t)}{\underline{u}_{\text {inor.phosph. }}(t)}=\frac{F_{0} \cdot q_{0}^{\text {inor.phosph. }}}{\underline{u}_{\text {inor.phosph. }}(t)}+H \cdot c_{2} \cdot \frac{\bar{u}_{\text {inor.phosph. }}(t)}{\underline{u}_{\text {inor.phosph. }}(t)}+k_{4} \cdot \frac{\underline{u}_{\text {oxyg. }}(t) \cdot \underline{u}_{\text {or.phosph. }}(t)}{\underline{u}_{\text {inor.phosph. }}(t)}+ \\
& +k_{5} \cdot \frac{\underline{u}_{\text {or.phosph. }}(t)}{\underline{u}_{\text {inor.phosph. }}(t)}-\left(F_{0}+H\right) \cdot c_{1}-k_{6} \cdot \underline{u}_{\text {oxyg. }}(t) \text {, } \\
& \left\{\frac{\dot{\bar{u}}_{\text {or.phosph. }}(t)}{\bar{u}_{\text {or.phosph. }}(t)}=\left(F_{0}+H\right) \cdot c_{1} \cdot \frac{u_{\text {or.phosph. }}(t)}{\bar{u}_{\text {or.phosph. }}(t)}+k_{7} \cdot \frac{\bar{u}_{\text {ph.pl. }}(t)}{\bar{u}_{\text {or.phosph. }}(t)}-\left(H+F_{\text {oxyg. }}+F_{0}\right) \cdot c_{2}-\right. \\
& -k_{8}-k_{9}-k_{1} \cdot T^{\circ} \\
& \frac{\underline{\dot{u}}_{\text {or.phosph. }}(t)}{\underline{u}_{\text {or.phosph. }}(t)}=\frac{F_{0} \cdot q_{0}^{\text {or.phosph. }}}{\underline{u}_{\text {or.phosph. }}(t)}+H \cdot c_{2} \cdot \frac{\bar{u}_{\text {or.phosph. }}(t)}{\underline{u}_{\text {or.phosph. }}(t)}+H \cdot c_{2} \cdot \frac{\bar{u}_{\text {ph.pl. }}(t)}{\underline{u}_{\text {or.phosph. }}(t)}+k_{9} \cdot \frac{\bar{u}_{\text {or.phosph. }}(t)}{\underline{u}_{\text {or.phosph. }}(t)}- \\
& -\left(F_{0}+H\right) \cdot c_{1}-k_{10}-k_{5}-k_{4} \cdot \underline{u}_{\text {oxyg. }}(t) \text {, } \\
& \frac{\dot{\bar{u}}_{\text {ph.pl. }}(t)}{\bar{u}_{\text {ph.pl. }}(t)}=k_{3} \cdot I \cdot T^{\circ} \cdot \bar{u}_{\text {inor.phosph. }}(t)-\left(H+F_{0}+F_{\text {oxyg. }}\right) \cdot c_{2}-k_{7} \text {, } \\
& \frac{\underline{\dot{u}}_{\text {oxyg. }}(t)}{\underline{u}_{\text {oxyg. }}(t)}=\frac{F_{0} \cdot q_{0}^{\text {oxyg. }}}{\underline{u}_{\text {oxyg. }}(t)}+\frac{H \cdot q_{1}^{\text {oxyg. }}}{\underline{u}_{\text {oxyg. }}(t)}-\left(F_{0}+H\right) \cdot c_{1}-\frac{k_{11}}{\underline{u}_{\text {oxyg. }}(t)}-k_{12} \cdot k_{4} \cdot \underline{u}_{\text {or.phosph. }}(t)-k_{5} \cdot \frac{\underline{u}_{\text {or.phosph. }}(t)}{\underline{u}_{\text {oxyg. }}(t)}
\end{aligned}
$$

and initial conditions

$$
\left\{\begin{array}{l}
\left.\bar{u}_{\text {inor.phosph. }}(t)\right|_{t=0}=\bar{u}_{\text {inor.phosph. }}^{0} ;\left.\underline{u}_{i n o r . p h o s p h .}(t)\right|_{t=0}=\underline{u}_{\text {inor.phosph. }}^{0} ;\left.\bar{u}_{\text {or.phosph. }}(t)\right|_{t=0}=\bar{u}_{\text {or.phosph. }}^{0} ; \\
\left.\underline{u}_{\text {or.phosph. }}(t)\right|_{t=0}=\underline{u}_{o r . p h o s p h .}^{0} ;\left.\bar{u}_{\text {ph.pl. }}(t)\right|_{t=0}=\bar{u}_{\text {ph.pl. }}^{0} ;\left.\underline{u}_{\text {oxyg. }}(t)\right|_{t=0}=\underline{u}_{o x y g .}^{0} .
\end{array}\right.
$$

In the model (1.3.1), (1.3.2) such designations and assumptions take place:

- the range of definition for each equation forming the system (1.3.1) is determined by the semi interval $(0, T]$;

- functions $\quad \bar{u}_{\text {inor.phosph. }}(t), \underline{u}_{\text {inor.phosph. }}(t), \bar{u}_{\text {or.phosph. }}(t), \underline{u}_{\text {or.phosph. }}(t), \bar{u}_{\text {ph.pl. }}(t) \quad$ and $\quad \underline{u}_{\text {oxyg. }}(t) \quad$ denote accordingly the desired amount of inorganic phosphorus above the layer of the Baltic Sea, where the salinity gradient is maximal (i.e. above the layer, where sea water salinity maximally changes - such a layer is called halocline: halocline is a vertical zone in the oceanic water column in which salinity changes rapidly with depth, located below the well-mixed: for instance, see http://www.britannica.com/EBchecked/topic/252980/halocline), inorganic phosphorus below the halocline, organic phosphorus above the halocline, organic phosphorus below the halocline, phytoplankton above the halocline and oxygen below the halocline at the moment of time $t \in[0, T]$ : $T$ is the given time period, during which the dynamics of oxygen condition of the Baltic Sea is studied; - constants $\bar{u}_{\text {inor.phosph. }}^{0}, \underline{u}_{i n o r . p h o s p h .}^{0}, \bar{u}_{\text {or.phosph. }}^{0}, \underline{u}_{o r . p h o s p h .}^{0}, \bar{u}_{\text {ph.pl. }}^{0}$ and $\underline{u}_{\text {oxyg. }}^{0}$ from the initial conditions (1.3.2) are supposed to be known before;

- values of constants (let's call them inner model constants) $I, T^{\circ}, H$ and parameters values (let's call them inner parameters of the model) $k_{i}(i=\overline{1,12}), c_{i}(i=1 ; 2), F_{0}, F_{\text {oxyg. }}^{\text {inor.phosph. }}, F_{\text {ph.pl. }}^{\text {inor.phosph. }}, F_{\text {oxyg. }}$, $q_{0}^{\text {inor.phosph. }}, q_{0}^{\text {or.phosph. }}, q_{0}^{\text {oxyg. }}, q_{1}^{\text {oxyg. }}$ of the differential equation system (1.3.1) are given below in 
accordance with research results [24]: $I=8$ hours; $T^{\circ}=8{ }^{\circ} \mathrm{C} ; H=2.125 \mathrm{~km} /($ twenty-four hours); $k_{1}=0.0041 /{ }^{\circ} \mathrm{C}$ per twenty-four hours; $k_{2}=0.00006931 /$ (twenty-four hours); $k_{3}=0.000000041 / \mathrm{t}$ Phosph. hour ${ }^{\circ} \mathrm{C} \cdot\left(\right.$ twenty-four hours); $k_{4}=0.0005371 / \mathrm{km}^{3} \mathrm{O}_{2} \cdot\left(\right.$ twenty-four hours); $k_{5}=0.001558$; $k_{6}=0.000002171 / \mathrm{km}^{3} \mathrm{O}_{2}$ (twenty-four hours); $k_{7}=0.0651 /$ (twenty-four hours); $k_{8}=0.00001846$ $1 /$ (twenty-four hours); $k_{9}=0.000221 /$ (twenty-four hours); $k_{10}=0.000221 /$ (twenty-four hours); $k_{11}=0.00042061 / \mathrm{km}^{3} \mathrm{O}_{2}$ (twenty-four hours); $k_{12}=0.0001991 / \mathrm{km}^{3} \quad \mathrm{O}_{2} \cdot$ (twenty-four hours); $c_{1}=0.00002765 \quad 1 / \mathrm{km}^{3} ; \quad c_{2}=0.0001053 \quad 1 / \mathrm{km}^{3} ; \quad F_{0}=1.308 \quad \mathrm{~km}^{3} /($ twenty-four hours $) ;$ $F_{\text {oxyg. }}^{\text {inor } \text { phosp. }}+F_{\text {ph.pl. }}^{\text {inorphosh. }}=28.7$ t Phosph./ (twenty-four hours); $F_{\text {oxyg. }}=1.308 \mathrm{~km} 3 /($ twenty-four hours); $q_{0}^{\text {inor.phosph. }}=0.001 \mathrm{~km}^{3}$ Phosph. $/ \mathrm{km}^{3} ; q_{0}^{\text {or. phosph. }}=0.003 \mathrm{~km}^{3}$ Phosph. $/ \mathrm{km}^{3} ; q_{0}^{\text {oxyg. }}=0.01 \mathrm{~km}^{3} \mathrm{O}_{2} /$ $\mathrm{km}^{3} ; q_{1}^{\text {oxyg. }}=0.01 \mathrm{~km}^{3} \mathrm{O}_{2} / \mathrm{km}^{3}$.

Remark 5. Due to the fact that almost 30 years have passed from the moment of publishing the work [24] and in this period significant geopolitical changes occurred in Europe, in particular, in the Baltic Sea countries (breakdown of the USSR; acquisition of sovereignty of the three Baltic States; decrease of industrial power of some of the Baltic Sea countries (Latvia, Lithuania, Estonia, Poland, Russia) and, as consequence, change of anthropogenic impact on the Baltic Sea by those countries; increase of industrialization of the developed Baltic Sea countries - Germany, Sweden, Finland, Denmark and other factors), it is evident that the values of model (1.3.1), (1.3.2) inner constants and parameters, which have been calculated in the work [24] and borrowed by us without any changes, obviously have to be specified more precisely. As it can be seen from the offered model (1.3.1)-(1.3.2), the corresponding changes/specifications of such inner constants and parameters of the model do not change the essence of the proposed model, except the coordinates of positive stationary points (one of the positive stationary points, within the small vicinity of which the model is stable will be the desired condition of the Baltic Sea!) of the system (1.3.1) will change: in [7,24] the Sjoberg model had two positive stationary points, one of them is stable and, therefore, it describes the real condition of oxygen in the Baltic Sea in the 70's of the XX century.

Remark 6. In the model (1.3.1), (1.3.2) units of modelling - tons of phosphorus ( $\mathrm{t}$ Phosph.) per twenty-four hours and cubic kilometre of oxygen $(\mathrm{km} 3)$, namely, measuring units of functions $\bar{u}_{\text {inor.phosph. }}(t), \underline{u}_{\text {inor.phosph. }}(t), \bar{u}_{\text {or.phosph. }}(t), \underline{u}_{\text {or.phosph. }}(t), \bar{u}_{\text {ph.pl. }}(t)$ are $\mathrm{t}$ Phosph/(twenty-four hours), but measuring units of function $\underline{u}_{\text {oxyg. }}^{0}$ are $\mathrm{km}^{3} \mathrm{O}_{2}$.

\section{Models of atmospheric pollution}

\subsection{The non-stationary model for determination of dynamics of hazardous substances concentration in the turbulent urban atmosphere with unknown velocity of air flow}

In this subsection a mathematical model is proposed for determination of dynamics and kinetics of harmful substances concentration, in particular, vehicle exhaust fumes in the turbulent atmosphere within the city scale. For the construction of mathematical model spatial-temporal variability of meteo-elements fields was taken into account as well as major turbulent characteristics of an atmosphere - irregularity, continuity, whirl-like nature, non-linearity, dissipativity, and diffusivity. Moreover, it was not supposed that the velocity of the turbulent air flow was previously known, and an assumption was made on piecewise constant coefficient of the turbulent and molecular diffusion and its dependence on vertical distance from the surface of the Earth that was a significant assumption regarding the vertical layering of the urban air. The fact that in the proposed model, alongside with the desired concentration of exhaust fumes, the unknown and desirable is also the function of turbulent air flow velocity, for determination of which a special separate mathematical model has been constructed (under the certain simplifying assumptions), which is interconnected with the main model - the model of determination of exhaust fumes concentration - allows thinking that the proposed model is in some sense a universal model (despite the fact that in [48] it is called "naive" model).

If to compare this model with the model proposed in the next subsection, then in the present model the following factors are not taken into account, which, depending on the class of atmospheric stability, can influence, even significantly, the final characteristics of the pollutant distribution process, including 
the exhaust fumes: (a) the factor of dry absorption of substances, composing emissions; (b) the factor of wet deposit and chemical transformations of the substances, composing emissions. Taking into account these two factors while constructing an adequate mathematical model, substantially changes the concept of model development: the essence and "appearance" of the model change radically. Exactly in this context the model proposed in this subsection is "naive" in comparison with the model, proposed in the next subsection.

So, considering the process of exhaust fumes distribution in a parallelepiped domain $\left[0, l_{1}\right] \times\left[0, l_{2}\right] \times\left[0, l_{3}\right]$, the offered mathematical model consists of finding the concentration $C^{\{n\}}\left(x_{1}, x_{2}, x_{3}, t\right)$ of the $n$-th $(n=\overline{1, N})$ pollutant at any arbitrary spatial point $\left(x_{1}, x_{2}, x_{3}\right)$ of the domain $\left[0, l_{1}\right] \times\left[0, l_{2}\right] \times\left[0, l_{3}\right]$ at the arbitrary moment of time $t \in[0, T]$ from

- the equation

$\frac{\partial C^{\{n\}}(x, t)}{\partial t}=\operatorname{div}\left(D(\vec{\vartheta}(x, t)) \cdot \overrightarrow{\operatorname{grad}} C^{\{n\}}(x, t)\right)$

$-\vec{\vartheta}(x, t) \cdot \overrightarrow{\operatorname{grad}} C^{\{n\}}(x, t), t \geq 0, x=\left(x_{1}, x_{2}, x_{3}\right): 0<x_{i}<l_{i}(i=\overline{1,3})$;

- from the initial condition

$\left.C^{\{n\}}(x, t)\right|_{t=0}=C_{0}^{\{n\}}(x), x=\left(x_{1}, x_{2}, x_{3}\right): 0 \leq x_{i} \leq l_{i}(i=\overline{1,3})$

- from the boundary conditions (with every fixed $j=\overline{0, M-1}$ )

$\left.\gamma_{i, 1, j}^{\{n\}} \cdot \frac{\partial C^{\{n\}}(x, t)}{\partial x_{i}}\right|_{x_{i}=a_{i, j}}-\left.\gamma_{i, 2, j}^{\{n\}} \cdot C^{\{n\}}(x, t)\right|_{x_{i}=a_{i, j}}=C_{i, j}^{\{n\}}\left(x /\left\{x_{i}\right\}, t\right), a_{i, j} \leq x_{i} \leq b_{i, j} \quad(i=\overline{1,3}), t \geq 0$,
$\left.\gamma_{i, 3, j}^{\{n\}} \cdot \frac{\partial C^{\{n\}}(x, t)}{\partial x_{i}}\right|_{x_{i}=b_{i, j}}+\left.\gamma_{i, 4, j}^{\{n\}} \cdot C^{\{n\}}(x, t)\right|_{x_{i}=b_{i, j}}=C_{i+3, j}^{\{n\}}\left(x /\left\{x_{i}\right\}, t\right), a_{i, j} \leq x_{i} \leq b_{i, j}(i=\overline{1,3}), t \geq 0$,

- from the conjugation conditions

$\left.C^{\{n\}}(x, t)\right|_{x_{3}=l_{3}^{\{j\}}-0}=\left.C^{\{n\}}(x, t)\right|_{x_{3}=l_{3}^{\{j\}}+0}, j=\overline{1, M-1}, 0 \leq x_{i} \leq l_{i} \quad(i=1,2)$,

$\left.D(\vec{\vartheta}(x, t)) \cdot \frac{\partial C^{\{n\}}(x, t)}{\partial x_{3}}\right|_{x_{3}=l_{3}^{\{j\}}-0}=\left.D(\vec{\vartheta}(x, t)) \cdot \frac{\partial C^{\{n\}}(x, t)}{\partial x_{3}}\right|_{x_{3}=l_{3}^{\{j\}}+0} \quad, j=\overline{1, M-1}, 0 \leq x_{i} \leq l_{i} \quad(i=1,2)$. place:

In the non-stationary initial-boundary problem (2.1.1)-(2.1.6) the following designations take $-D(\vec{\vartheta}(x, t))$ denotes the coefficient of the turbulent and molecular diffusion, which according to the abovementioned assumption, is a piecewise-constant function of the type

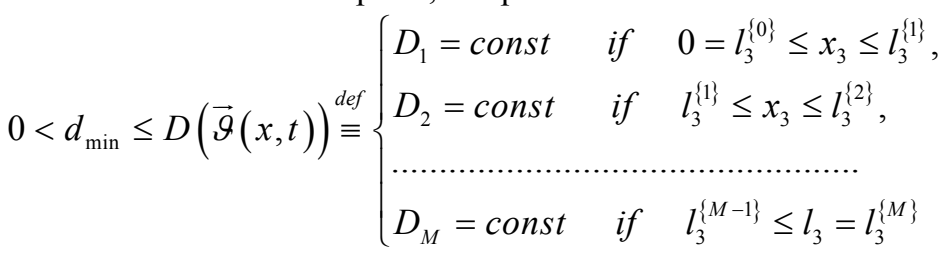

for $\forall x_{i} \in\left[0, l_{i}\right],(i=1,2)$, where $M$ is a number of parallel layered media to the plane $X_{1} O X_{2}$ in respect to the vertical axis $\mathrm{OX}_{3}$;

- for simplification the points of boundary layers are denoted as $a_{i, j}$ and $b_{i, j}$ :

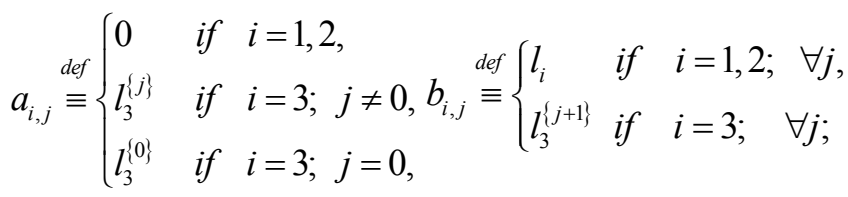

- $\vec{\vartheta}(x, t) \equiv \vartheta\left(x_{3}, t\right)$ denote the unknown vector-function of the averaged velocity of turbulent atmospheric air, which is the solution of the following non-linear problem: 


$$
\begin{aligned}
& \frac{\partial \vartheta\left(x_{3}, t\right)}{\partial t}=\frac{\partial}{\partial x_{3}}\left(D\left(\vartheta\left(x_{3}, t\right)\right) \cdot \frac{\partial \vartheta\left(x_{3}, t\right)}{\partial x_{3}}\right)-\vartheta\left(x_{3}, t\right) \cdot \frac{\partial \vartheta\left(x_{3}, t\right)}{\partial x_{3}}+P\left(x_{3}, t ; g\right), 0<x_{3}<l_{3}, t>0 \text {; } \\
& \left.\vartheta\left(x_{3}, t\right)\right|_{t=0}=\vartheta_{\text {initial }}\left(x_{3}\right), 0 \leq x_{3} \leq l_{3} \text {; } \\
& \left.\vartheta\left(x_{3}, t\right)\right|_{x_{3}=l_{3}^{(i, 3}}=\vartheta_{i}(t), t \geq 0, i=\overline{0, M} \\
& \vartheta_{\text {initial }}\left(l_{3}^{\{i\}}\right)=\vartheta_{i}(0), i=\overline{0, M} \text {; } \\
& \left.\vartheta\left(x_{3}, t\right)\right|_{x_{3}=l_{3}^{[i]}-0}=\left.\vartheta\left(x_{3}, t\right)\right|_{x_{3}=l_{3}^{[i]}+0}, i=\overline{1, M-1}, t \geq 0 \text {; } \\
& \left.D\left(\vartheta\left(x_{3}, t\right)\right) \cdot \frac{\partial \vartheta\left(x_{3}, t\right)}{\partial x_{3}}\right|_{x_{3}=l_{3}^{i i^{i}}-0}=\left.D\left(\vartheta\left(x_{3}, t\right)\right) \cdot \frac{\partial \vartheta\left(x_{3}, t\right)}{\partial x_{3}}\right|_{x_{3}=l_{3}^{i i^{3}}+0}, \quad i=\overline{1, M-1}, t \geq 0 .
\end{aligned}
$$

In the problem (2.1.1)-(2.1.13) the known initial data are the constants $g \approx 9.8 \mathrm{~m} / \mathrm{c}^{2}$ (gravitational acceleration), $\quad N \in \mathbb{N}, \quad M \in \mathbb{N}, \quad T \in \mathbb{R}_{+}^{1}, \quad D_{j} \in \mathbb{R}_{+}^{1}(j=\overline{1, M})$, $l_{i}^{\{j\}} \in \mathbb{R}_{+}^{1}(i=\overline{1,3} ; \quad j=\overline{0, M}), \quad \gamma_{i, k, j}^{\{n\}} \in \mathbb{R}_{+}^{1}(i=1,2 ; \quad k=\overline{1,4} ; \quad j=\overline{0, M-1})$, moreover, for $\forall n=\overline{1, N}$ holds

$$
\gamma_{i, k, j}^{\{n\}}=\left\{\begin{array}{lll}
1 & \text { if } j=0 ; & i=1 ; \quad k=1,3, \\
0 & \text { if } j=0 ; & i=1 ; \quad k=2,4, \\
\gamma_{i, k, j}^{\{n\}}>0 \text { if } \quad j \neq 0 ; & \forall i, k ;
\end{array}\right.
$$

as well as functions $\vartheta_{\text {initial }}\left(x_{3}\right), \quad \vartheta_{i}(t)(i=\overline{1, M}), \quad P\left(x_{3}, t ; g\right)$ (power of external sources), $C_{0}^{\{n\}}(x)(\forall n=\overline{1, N}), C_{i, j}^{\{n\}}(\cdot, t) \quad(i=\overline{1,6} ; j=\overline{0, M-1})$, moreover, for $\forall n=\overline{1, N}$ holds

$$
C_{i, j}^{\{n\}}(\cdot, t)=\left\{\begin{array}{l}
C_{i, j}^{\{n\}}(\cdot, t) \text { if }\{j=0\} \wedge\{i=3,6\} ; \\
0 \text { otherwise }
\end{array}\right.
$$

Finally, in the problem (2.1.1), (2.1.7), (2.1.14), (2.1.15) in respect to concentration it is supposed that the initial function $C_{0}^{\{n\}}(x)$ and the boundary functions $C_{i, j}^{\{n\}}(\cdot, t)$ are satisfying the corresponding consistency conditions (see [45]) for each $n=\overline{1, N}$ of exhaust fumes. In the complete model (2.1.1)(2.1.15) the desired functions are concentration $C^{\{n\}}\left(x_{1}, x_{2}, x_{3}, t\right)$ of the $n$-th $(n=\overline{1, N})$ pollutant and the averaged velocity $\vartheta\left(x_{3}, t\right)$ of the atmospheric turbulent flow.

Remark 7. In the formulated model (2.1.1)-(2.1.15) the axis $O X_{1}$ is directed along the considered part of the city street loaded with vehicular traffic, i.e. it is supposed that along this axis the length of the considered street part is located; the axis $\mathrm{OX}_{2}$ is directed along the width of this street, but the axis $\mathrm{OX}_{3}$ is directed along the height of the considered domain of the city. In other words, the spatial domain of the mathematical model (2.1.1)-(2.1.15) has the form of parallelepiped layered along the axis $O X_{3}$, in which at first, the length/width/height are characterized by the coordinate axis $O X_{1} / O X_{2} / O X_{3}$ correspondingly, and, secondly, all the layers are parallel to the surface $\mathrm{X}_{1} \mathrm{OX}_{2}$.

Remark 8. In the formulated model (2.1.1)-(2.1.15) the boundary conditions (2.1.3), (2.1.4) are the conditions of mixed type, namely:

- for the first layer (the near-surface layer) $0+0=l_{3}^{\{0\}}+0 \leq x_{3} \leq l_{3}^{\{1\}}-0$;

- on the wall of the parallelepiped (see Remark 3) $\left\{x_{1}=0+0,0 \leq x_{2} \leq l_{2}, 0 \leq x_{3} \leq l_{3}^{(i)}\right\}$, which is perpendicular to the axis $O X_{1}$ at the point $x_{1}=0+0$ (that is, on the wall, which reflects the beginning of the considered area), and on the wall $\left\{x_{1}=l_{1}-0,0 \leq x_{2} \leq l_{2}, 0 \leq x_{3} \leq l_{3}^{\{1\}}\right\}$, which is perpendicular to the 
axis $O X_{1}$ at the point $x_{1}=l_{1}-0$ (that is, on the wall, which reflects the end of the considered area), the boundary conditions are given as the conditions of the third type (i.e. the so-called the Newton conditions);

- on the other two walls, which are perpendicular to the axis $O X_{2}$ at points $x_{2}=0+0$ and $x_{2}=l_{2}-0$ (that is, on the walls, reflecting the buildings along the roadside of the considered street), the boundary conditions are given as the conditions of the second type (i.e. the so-called the Neumann conditions);

- for all the other layers $l_{3}^{\{1\}}+0 \leq x_{3} \leq l_{3}-0$ on all the walls of the parallelepiped the boundary conditions are given as the conditions of the first type (i.e. the so-called the Dirichlet conditions).

Depending on what type of measuring equipment and technical devices the experiment performers have (that is, experts performing measuring of pollutant concentrations) for provision of fulfilment of the initial condition and boundary conditions in the proposed model, it is possible to consider instead of the boundary conditions (2.1.3), (2.1.4) the other boundary conditions, which can appear to be more beneficial from the researcher's point of view. For example, if instead of formulae (2.1.7), (2.1.14), (2.1.15), respectively, to write

$$
\begin{aligned}
& a_{i, j}=\left\{\begin{array}{c}
0 \quad \text { if } \quad i=1,2 ; \\
l_{3}^{(j)} \quad \text { if } \quad i=3 ; j \neq 0 ; \\
l_{3}^{(0)}=0 \quad \text { if } \quad i=3 ; j=0,
\end{array} \quad b_{i, j}=\left\{\begin{array}{l}
l_{i} \text { if } \quad i=1,2 ; \\
l_{3}^{(j+1)} \quad \text { if } \quad i=3,
\end{array}\right.\right. \\
& \gamma_{i, k, j}^{(n)}=\left\{\begin{array}{l}
\gamma_{i, k, j}^{(n)}>0 \quad \text { if } j \neq 0, \forall i, k ; \\
0 \text { if } j=0, k=1,3, \forall i ; \\
-1 \quad \text { if } j=0, k=2, \forall i \\
1 \text { if } j=0, k=4, \forall i,
\end{array}\right.
\end{aligned}
$$

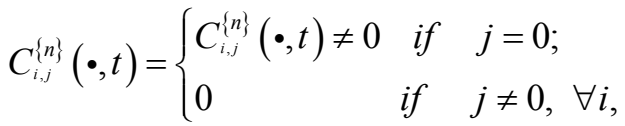

the boundary conditions (2.1.3), (2.1.4) of other nature will be determined, namely:

- for the first layer (for the near-surface layer) $0+0=l_{3}^{\{0\}}+0 \leq x_{3} \leq l_{3}^{\{1\}}-0$ on all the walls of parallelepiped the boundary conditions are given as the Dirichlet conditions;

- for all the other layers $l_{3}^{\{1\}}+0 \leq x_{3} \leq l_{3}-0$ on all the walls of the parallelepiped the boundary conditions are given as the Newton conditions.

If instead of $(2.1 .7),(2.1 .14),(2.1 .15)$, respectively, to write

$b_{i, j}=\left\{\begin{array}{l}l_{i} \quad \text { if } \quad i=1,2 ; \\ l_{3}^{(j+1)} \text { if } \quad i=3,\end{array}\right.$

$\gamma_{i, k, j}^{(n)}=\left\{\begin{array}{l}\gamma_{i, k, j}^{(n)}>0 \quad \text { if } \quad i \neq 1, \forall j, k ; \\ 1 \quad \text { if } i=1, k=1,3, \forall j ; \\ 0 \quad \text { if } i=1, k=2,4, \forall j,\end{array}\right.$

$C_{i, j}^{\{n\}}(\cdot, t)= \begin{cases}C_{i, j}^{\{n\}}(\cdot, t) \neq 0 & \text { if } \quad\{j=0\} \wedge\{i=2,3,5,6\} ; \\ 0 & \text { otherwise, }\end{cases}$

then, by doing this the boundary conditions (2.1.3), (2.1.4) of another nature are defined, namely:

- for all the layers $0=l_{3}^{\{0\}}+0 \leq x_{3} \leq l_{3}$ on the walls, perpendicular to the axis $O X_{1}$ at the points $x_{1}=0+0$ (that is, on the walls, reflecting the beginning of the considered area) and $x_{1}=l_{1}-0$ (that is, on the walls reflecting the end of the considered area), the boundary conditions are defined as the Neumann conditions;

- for all the layers $0=l_{3}^{\{0\}}+0 \leq x_{3} \leq l_{3}$ on all the other walls perpendicular to the axis $O X_{2}$ at the point $x_{2}=0+0$ and $x_{2}=l_{2}-0$ (that is, on the walls, reflecting buildings along the sides of the considered street), the boundary conditions are defined as the conditions of the Newton conditions. 
If instead of (2.1.7), (2.1.14), (2.1.15), respectively, to write

$$
\begin{aligned}
& a_{i, j}=\left\{\begin{array}{l}
0 \quad \text { if } \quad j=0, i=1,3 ; \\
0 \quad \text { if } \quad j \neq 0, i=1,2 ; b_{i, j} \\
l_{3}^{(j)} \quad \text { if } j \neq 0, i=3,
\end{array}=\left\{\begin{array}{l}
l_{i} \quad \text { if } \quad i=1,2, \forall j ; \\
l_{3}^{(j+1)} \quad \text { if } \quad i=3, \forall j,
\end{array}\right.\right. \\
& \gamma_{i, k, j}^{(n)} \in \mathbb{R}_{+}^{1}(i=1,2 ; k=\overline{1,4} ; j=\overline{0, M-1}) \text { are given numbers, } \\
& C_{0}^{\{n\}}(x), C_{i, j}^{\{n\}}(\bullet, t)(i=1,6 ; j=\overline{0, M-1}) \text { are given functions, }
\end{aligned}
$$

then by doing these boundary conditions (2.1.3)-(2.1.4) of another nature will be defined, namely: for all the layers on all the walls of the parallelepiped the boundary conditions are defined only as the conditions of the Newton conditions. It is obvious that in this case the boundary conditions are of the mixed type and for its provision more sophisticated and precise measurements are required.

Other types of boundary conditions are also possible. In present research the boundary conditions (2.1.3), (2.1.4) are defined by the formulae (2.1.7), (2.1.14), and (2.1.15). However, the obtained results can be easily distributed also for the mathematical models (2.1.1)-(2.1.6), (2.1.8)-(2.1.13), where the boundary conditions in respect to the desirable concentration $C^{\{n\}}\left(x_{1}, x_{2}, x_{3}, t\right)$ are defined either by formulae (2.1.16)-(2.1.18), or by formulae (2.1.19)-(2.1.21), or by formulae (2.1.22)-(2.1.24).

Concluding this remark it would be worth to recall that when the boundary condition in respect to the concentration is given as Dirichlet condition, then it is necessary to measure the concentration on the corresponding boundary (on the surface, on the walls), when the boundary condition is given as Neumann condition, there is no need in measuring concentration, but it is required to measure the "flow" of concentration in the corresponding boundary of the considered domain; but if the boundary condition is given as Newton condition, it is necessary to measure concentration by taking into account the moleculardiffusive exchange with the ambient environment, what is the most important and the most sophisticated measurement process, requiring the corresponding technical means and scientific potential.

Remark 9. It is possible to assume that the number of layers from the Earth surface till the desired height $l_{3}$ is equal to four, that is $M=4$, and the boundaries of each layer are empirically determined, moreover, the upper boundary of the most distant layer from the Earth surface (that is, the boundary of the fourth layer) is equal to 24 metres that corresponds to the average height of buildings in Riga.

\subsection{Molecular-kinetic complex model of distribution of hazardous substances for multi-layered computation domain of sophisticated configuration taking into account the wind field and urban area development (i.e. quasi-hilly landscape)}

In this subsection a mathematical model is proposed for distribution of harmful substances in the turbulent atmosphere. The proposed model is a transport-diffusion model of distribution of harmful substances, and it is constructed on the basis of the parabolic type equations system taking into account the substance preservation law. In this model there are also taken into consideration the following: laws of transfer, including intensive transfer; pollutants concentration gradient changing factor; presence of sources and sinks due to physical-chemical processes; main properties of the wind field taking into account the quasi-hilly landscape; general laws of the air masses turbulent motion; the fact that distribution of pollutants can be done from several sources of qualitatively different type; laws of dry absorption of substances, composing the pollutants; laws of wet deposit and chemical transformation of substances, composing emissions.

Finally, let us notice that in the model given below the whole three-dimensional domain, where distribution of harmful contaminants is studied, is divided into layers of variable height in respect to the vertical (that is, in respect to the outer normal to the Earth surface). To activate the model some initial data are required, namely, the field of wind velocities over the area of the complex terrain; coefficients of vertical and horizontal turbulence; characteristic height of the mixing layer, within which there is an intensive process of pollutant transfer in the atmosphere (it is known that it could be ranged from $250 \mathrm{~m}$ up to $2 \mathrm{~km}$ ); wind velocity; height of the upper boundary of the mixing layer; the flux level of deposition; class of atmospheric stability; temperature gradient. It is important to stress that all the required initial data are available and can be relatively easily acquired from meteorological equipment.

So, the proposed mathematical model is rooted in determination of sulphur dioxide $\mathrm{SO}_{2}(\mathrm{IV})$ (when $j=1$ ) and anion of the sulphuric acid $S O_{4}^{=}$(when $j=2$ ) concentration $C_{j}^{\{i\}}(x, y ; t) \quad\left(i=\overline{1, n_{z}}\right)$ in the $n_{z}$-layered domain $L_{x} \times L_{y}$ from the system of equations 


$$
\left\{\begin{array}{l}
\frac{\partial\left(h^{\{i\}} \cdot C_{1}^{\{i\}}\right)}{\partial t}+d i v_{x, y}\left(h^{\{i\}} \cdot C_{1}^{\{i\}} \cdot V_{\text {wind }}^{\{i\}}\right)-\operatorname{div}_{x, y}\left(K_{\text {horiz. }}^{\{i\}} \cdot h^{\{i\}} \cdot \operatorname{grad}_{x, y} C_{1}^{\{i\}}\right)+\left(V_{d r y_{1}}+V_{\text {humidi }}\right) \cdot C_{2}^{\{i\}}- \\
-V_{\text {transform. }} \cdot h^{\{i\}} \cdot C_{1}^{\{i\}}=D_{1}^{\{i\}}\left(C_{1}^{\{i\}}\right)+\alpha \cdot h^{\{i\}} \cdot F_{\text {emission }}^{\{i\}}, \quad(x, y, z) \in L_{x} \times L_{y}, t \in(0, T) ; \forall i=\overline{1, n_{z}}, \\
\frac{\partial\left(h^{\{i\}} \cdot C_{2}^{\{i\}}\right)}{\partial t}+\operatorname{div}_{x, y}\left(h^{\{i\}} \cdot C_{2}^{\{i\}} \cdot V_{\text {wind }}^{\{i\}}\right)-\operatorname{div}\left(K_{\text {horiz }}^{\{i\}} \cdot h^{\{i\}} \cdot \operatorname{grad}_{x, y} C_{2}^{\{i\}}\right)+\left(V_{d r y_{2}}+V_{\text {humid }}\right) \cdot C_{1}^{\{i\}}- \\
-V_{\text {transform. }} \cdot h^{\{i\}} \cdot C_{2}^{\{i\}}=D_{2}^{\{i\}}\left(C_{2}^{\{i\}}\right)+\alpha \cdot h^{\{i\}} \cdot F_{\text {emission }}^{\{i\}}, \quad(x, y, z) \in L_{x} \times L_{y}, t \in(0, T) ; \forall i=\overline{1, n_{z}} .
\end{array}\right.
$$

In the (2.2.1) system the following designations take place:

- $n_{z}$ is the number of layers, each of the layers is perpendicular to the outer normal $\vec{n}$ to the Earth surface: in the proposed model (2.2.1) the direction of the coordinate axis $O Z$ coincides with the direction of the outer normal $\vec{n}$;

- $L_{x}$ and $L_{y}$ are linear sizes of the considered domain, where the dynamics of pollutant (sulphur dioxide and sulphuric acid) distribution is investigated;

- $T$ is the time of investigation for the dynamics of harmful substances (sulphur dioxide and sulphuric acid) distribution;

- $h^{\{i\}}$ is the thickness of the $i$-th layer $\left(i=\overline{1, n_{z}}\right) ; V_{\text {wind }}^{\{i\}}$ is the velocity of the wind in the i-th layer $\left(i=\overline{1, n_{z}}\right) ; V_{d r y_{1}}$ is the velocity of dry deposit of the sulphur dioxide $S O_{2}(I V) ; V_{d r y_{2}}$ is the velocity of dry deposit of the sulphuric acid $\mathrm{SO}_{4}^{=} ; V_{\text {humid }}$ is the velocity of wet deposit of the sulphur dioxide $\mathrm{SO}_{2}(\mathrm{IV}) ; V_{\text {humid }}$ is the velocity of the wet deposit of the sulphuric acid $\mathrm{SO}_{4}^{=}$;

- $V_{\text {transform. }}$ is the velocity of the chemical transformation of the sulphur dioxide $\mathrm{SO}_{2}(\mathrm{IV})$ into the sulphuric acid $\mathrm{SO}_{4}^{=} ; \alpha$ is the amount of sulphur dioxide $\mathrm{SO}_{4}^{=}$in the emitted impurities; $F_{\text {emission }}^{\{i\}}$ is the field of emission in the $i$-th layer $\left(i=\overline{1, n_{z}}\right)$;

- $K_{\text {horiz. }}^{\{i\}}$ is the coefficient of the horizontal turbulent diffusion in the $i$-th layer $\left(i=\overline{1, n_{z}}\right)$, which is calculated by the following formula (see [48]):

$$
K_{\text {horiz. }}^{\{i\}} \stackrel{\text { def }}{\equiv} \max \left(\frac{1}{2},\left|V_{\text {wind }}^{\{i\}}\right|\right) \cdot\left(\beta^{\{i\}}\right)^{2} \cdot H^{\{i\}},
$$

where $\beta^{\{i\}}$ denotes the angle (in radians) of the horizontal fluctuation of the wind direction in the $i$-th layer $\left(i=\overline{1, n_{z}}\right)$, but $H^{\{i\}}$ denotes the height (in metres) of the $i$-th layer of mixing $\left(i=\overline{1, n_{z}}\right)$;

- $D_{1}^{\{i\}}\left(C_{1}^{\{i\}}\right)$ is the coefficient of vertical turbulent diffusion for the sulphur dioxide $\mathrm{SO}_{2}(\mathrm{IV})$ in the $i$-th layer $\left(i=\overline{1, n_{z}}\right)$, which is calculated according to the following formula (see [48]):

$$
D_{1}^{\{i\}}\left(C_{1}^{\{i\}}\right) \stackrel{\text { def }}{2}\left\{\begin{array}{l}
2 \cdot D^{\{i\}} \cdot \frac{C_{1}^{\{i+1\}}-C^{\{i\}}}{h^{\{i\}}+h^{i i 1\}}} \quad \text { if } \quad i=1, \\
2 \cdot D^{\{i\}} \cdot \frac{C_{1}^{\{i+1\}}-C_{1}^{\{i\}}}{h^{\{i\}}+h^{\{i+1\}}}-2 \cdot D^{\{i-1\}} \cdot \frac{C_{1}^{\{i\}}-C_{1}^{\{i-1\}}}{h^{\{i-1\}}+h^{\{i\}}} \quad \text { if } \quad i=\overline{2, n_{z}-1}, \\
-2 \cdot D^{\{i-1\}} \cdot \frac{C_{1}^{\{i\}}-C_{1}^{\{i-1\}}}{h^{\{i\}}+h^{\{i-1\}}} \quad \text { if } \quad i=n_{z} ;
\end{array}\right.
$$

where $D^{\{i\}}$ denotes the coefficient of the turbulent diffusion in the $i$-th layer $\left(i=\overline{1, n_{z}}\right)$;

- $D_{2}^{\{i\}}\left(C_{2}^{\{i\}}\right)$ is the coefficient of the vertical turbulent diffusion for the sulphuric acid $\mathrm{SO}_{4}^{=}$in the $i$-th layer $\left(i=\overline{1, n_{z}}\right)$, which is calculated according to the following formula (see [48]): 


$$
D_{2}^{\{i\}}\left(C_{2}^{\{i\}}\right) \stackrel{d e f}{2}\left\{\begin{array}{l}
2 \cdot D^{\{i\}} \cdot \frac{C_{2}^{\{i+1\}}-C_{2}^{\{i\}}}{h^{\{i\}}+h^{\{i+1\}}} \quad \text { if } \quad i=1, \\
2 \cdot D^{\{i\}} \cdot \frac{C_{2}^{\{i+1\}}-C_{2}^{\{i\}}}{h^{\{i\}}+h^{\{i+1\}}}-2 \cdot D^{\{i-1\}} \cdot \frac{C_{2}^{\{i\}}-C_{2}^{\{i-1\}}}{h^{\{i-1\}}+h^{\{i\}}} \quad \text { if } \quad i=\overline{2, n_{z}-1}, \\
-2 \cdot D^{\{i-1\}} \cdot \frac{C_{2}^{\{i\}}-C_{2}^{\{i-1\}}}{h^{\{i\}}+h^{\{i-1\}}} \quad \text { if } \quad i=n_{z} ;
\end{array}\right.
$$

\section{Conclusions}

In the present paper there is proposed a complex of continuous qualitative models having dynamic parameters for analysis, evaluation and forecast of aquatic (water reservoirs, lakes and the Baltic Sea) and atmospheric ecosystems in Latvia. All the constructed models (there are 5 models, three of which are dealing with modelling of diverse aspects of aquatic systems, while other two are modelling the dynamics of atmosphere pollution processes) are described in terms of differential equations and mathematical physics and are considered to be evolutional models. Below it is given a short description of the models proposed.

The first model is aimed at discovering the pollutant concentration dynamics in the Baltic Sea. This model can be used as the primary model for the better monitoring of the Baltic Sea. The second model is designed to determine the basic characteristics of nitrogen circulation in the natural aquatic environments. This model allows reducing substantially (in comparison with the other models constructed to this date and known to the authors of this paper) the uncertainty in the parameters of the sophisticated process of circulation in the inhomogeneous media, which is typical for natural aquatic environment with powerful sources and sinks. Let us note that it is possible to consider minimizing the number of uncertain model parameters issue by (a) identifying relationships imposed on the parameters, (b) finding non-trivial special points of the system-model, and taking into account those points found in a consequent way for the several structures of the circulation processes following the conditions of stability maintenance. In further studies authors plan to carry out the abovementioned minimization for the uncertain model parameters number. The third is a mathematical model that allows determining the sensitivity of oxygen condition in the Baltic Sea. This model provides a possibility to (a) identify those features of oxygen condition dynamics, which are not revealed during the regular enumeration and/or using pure statistical methods of parameters evaluation; (b) to identify qualitative properties of the oxygen condition dynamics, which reduce significantly the uncertainty in the complex interrelations between dynamics parameters and the environment, making it possible to forecast the anthropogenic impact on the ecosystem with a high degree of accuracy, and, therefore, to identify existing trends in the ecosystem of the sea. However, it should be noted that this model cannot be used for the study of the seasonal Baltic Sea ecosystem dynamics in the conditions of aerobic and anaerobic states being below the halocline level, and this is regarded to be a limitation of the model. For this reason, the third model can be used only as a primary model for identification of condition that leads to anaerobic zones growth strengthening in the Baltic Sea.

The fourth proposed mathematical model is devoted to the determination of dynamics and kinetics of the harmful substances concentration, in particular, the vehicular traffic exhaust fumes in the turbulent atmosphere within the city-scale. The important feature of this model is the fact that it is not assumed a priori known velocity of turbulent flow of air, and in order to find the unknown turbulent velocity it is constructed the separate mathematical model, which is interconnected with a general model - the model of determining the concentration of exhaust fumes. Particularly in this context the provided model in some sense is regarded to be a universal model. However, the number of shortcomings of this model includes the following constraints, which, depending on the class of atmospheric stability may affect, even substantially, the resulting characteristics of pollutant distribution process, including exhaust fumes: (a) the factor of dry absorption of substances, composing emissions; (b) the factor of wet deposit and chemical transformations of the substances, composing emissions. Taking into account these two factors while constructing an adequate mathematical model, substantially changes the concept of model development: the essence and "appearance" of the model change radically. Exactly in this context this mathematical model is "naive" in comparison with the fifth model (the last one from proposed models). The fifth model of distribution of hazardous substances in the turbulent atmosphere is a transportdiffusion model of harmful containments transfer. In this model there are taken into consideration as follows: (a) laws of transfer, including intensive transfer; (b) pollutant concentration gradient changing factor; (c) presence of sources and sinks due to physical-chemical processes; (d) main properties of 
the wind field taking into account the quasi-hilly landscape; (e) general laws of the air masses turbulent motion; (f) the fact that distribution of pollutants can occur from several sources having qualitatively versatile nature; $(\mathrm{g})$ laws of dry absorption of substances, composing the pollutants; (h) laws of wet deposit and chemical transformation of substances, composing emissions. Finally, let us notice that in this model the whole three-dimensional domain, where distribution of harmful contaminants is studied, is divided into layers of variable height in respect to the vertical (that is, in respect to the outer normal to the Earth surface). To activate the model the following initial data are required, namely, the field of wind velocities over the area of the complex terrain; coefficients of vertical and horizontal turbulence; characteristic height of the mixing layer, within which there goes an intensive process of pollutant transfer in the atmosphere; wind velocity; height of the upper boundary of the mixing layer; the flux level of deposition; class of atmospheric stability; temperature gradient. Besides, it is important to emphasize that all the required initial data are available and can be relatively easily acquired by means of using meteorological equipment.

To conclude with, let us note that authors of this research are intended to continue the further investigation taking the benefit of both qualitative and quantitative studies for all five models as well as to develop the stable analytical and numerical methods for their solution ensuring the corresponding computer-based implementation.

\section{Acknowledgments}

The present article was executed within the framework of the following two International Projects (Grants): (1) The European Social Fund (ESF) Project No. 1DP/1.1.1.2.0/09/APIA/VIAA/142 "Elaboration of effective analytical and numerical methods for solving of direct and inverse mathematical physics problems in material, economics and environment sciences" (for the first author); (2) The European COST Action TU0902 "Integrated assessment technologies to support the sustainable development of urban areas" (for both authors).

\section{References}

1. Marchuk, G. I. (1982). Mathematical modelling in environmental problem. Moscow: Science.

2. Marchuk, G. I. and Kondratyev, K. Y. (1992). Priorities of global ecology. Moscow: Science.

3. Marchuk, G. I. (1973). Numerical solution of atmospheric and ocean dynamics problems. Moscow: Science.

4. Jennifers, J. (1981). Introduction to system analysis: application for ecology. Moscow: World.

5. Alekseyev, V. V., Kiselyeva, S. V., Lappo, S. S. (2005). Laboratory models of physical processes. Moscow: Science.

6. Serdiutskaya, L. F. (2000). Study of mathematical models of environmental systems using multivariate factor analysis. International Journal on Engineering Simulation, 17, 417-428. ISSN 1468-1137.

7. Sjoberg, S. (1980). A mathematical and conceptual framework for models of the pelagic ecosystems of the Baltic Sea. Contributions from the Asko Laboratory (No 1). Stockholm: University of Stockholm.

8. Bolin, B. (1972). Model studies of the Baltic Sea: Ambio Special Report. Stockholm: Institute of Meteorology, University of Stockholm. (Report GH-4, No 1)

9. Venkatram, A., Wyngaard, J. C. (1988). Lectures on Air Pollution Modeling. Boston: American Meteorological Society.

10. Barabasheva, Yu. M., Brodsky, L. I., Devyatkova, G. I. (1987). About evaluation of parameters in the point model of aquatic ecosystem: Theoretical ecology. Moscow: Lomonosov Moscow State University Publishing.

11. Penenko, V. V., Aloyan, A. E. (1985). Models and methods for the problems of environmental protection. Moscow: Science.

12. Guseynov, Sh. E., Kopytov, E. A., Schiptsov, O. V. (2010). Mathematical models of an exhaust concentration dynamics in urban atmosphere: Monograph. Riga: Transport and Telecommunication Institute.

13. Guseynov, Sh. E., Solovyov, Y. O., Schiptsov, O. V. (2010). Construction and investigation of one continuous nonstationary 3D mathematical model for monitoring of noise pollution in the area surrounding an airport. Transport and Telecommunication, 11(3), 4-14.

14. Guseynov, Sh. E., Kopytov, E. A., Grishin, S., Schiptsov, O. V., Rimshans, J. S. (2010). Mathematical model for determination of exhaust concentration dynamics in urban atmosphere 
under unknown turbulent air flow velocity. Technika, Eksploatacija, Systemy Transportowe, 6, 7. Retrieved December 22, 2011, from http://autobusy-test.com.pl/pdf/GUSEYNOV\%20Sharif\%20et\%20al.pdf

15. Grishin, S., Rimshans, J. S., Kopytov, E. A., Guseynov, Sh. E., Schiptsov O. V. (2010). Timedependent problem for determination of exhaust concentration in urban transport system. Technika, Eksploatacija, Systemy Transportowe, 6, 10. Retrieved December 22, 2011, from http://autobusy-test.com.pl/pdf/GRISHIN\%20Stanislav\%20et\%20al.pdf

16. Guseynov, Sh. E., Rimshans, J. S., Kopytov, E. A. (2011). Solution of the Model of Exhaust Concentration Dynamics in Urban Atmosphere under Unknown Turbulent Air Flow Velocity. International Journal of Procedia Environmental Sciences, Series: Urban Environmental Pollution, 4, 35-42.

17. Solovyov, Y. O., Schiptsov, O. V., Guseynov, Sh. E. (2010). Development and investigation of the unsteady 3D mathematical model for continued ecological monitoring in the airport area. In Proceedings of the $10^{\text {th }}$ International Conference "Reliability and Statistics in Transportation and Communication" (RelStat'10), Riga, Latvia, October 20-23, 2010 (pp. 403-412). Riga: Transport and Telecommunication Institute.

18. Guseynov, Sh. E., Kopytov, E. A., Grishin, S., Schiptsov, O. V., Rimshans, J. S. (2008). Mathematical model for determination of exhaust concentration dynamics in urban atmosphere under unknown turbulent airflow velocity. In Proceedings of the $8^{\text {th }}$ International Conference "Reliability and Statistics in Transportation and Communication (RelStat'08)", Riga, Latvia, October 15-18, 2008 (pp. 9-14). Riga: Transport and Telecommunication Institute.

19. Rimshans, J. S., Esau, I. N., Zilitenkevich, S. S., Guseynov, Sh. E. (2008). Analytical-Numerical Solution for the One Dimensional PBL Turbulence Model. In Proceedings of the $18^{\text {th }}$ Symposium on Boundary Layers and Turbulence under the aegis of the American Meteorological Society, Stockholm, Sweden June 09-13, 2008. Retrieved December 22, 2011, from http://ams.confex.com/ams/pdfpapers/139877.pdf

20. Davidson, P. A. (2006). Turbulence. An introduction for scientists and engineers. Oxford: Oxford University Press, XIX+657 p.

21. Zudema, G., Borm, G. J., Alcamo, J. (1994). Simulating changes in global Land cover as affected by economic and climatic factors. International Journal on Water, Air and Soil Pollution, 76(1-2), 163-198.

22. Belyaev, V. I., Korenyuk, Ye. D., Hrusch, V. K. (2001). Computer modelling of the subsurface water circulation and pollution dynamics. Dnepropetrovsk: Science and Education.

23. Serdyutskaya, L. F. (1997). About some aspects of factorial analysis application for the problems of environmental simulation. In Modelling and diagnostics of the sophisticated processes and systems (pp. 35-40). Kiev: Scientific thought.

24. Sjoberg, S., Wulff, F., Wahllstrom, P. (1972). Computer Simulations of Hydrochemical and Biological processes in the Baltic. Contributions from the Asko Laboratory (No 1). Stockholm: University of Stockholm.

25. Terehina, A. Yu. (1986). Data analysis using the multidimensional scaling methods. Moscow: Science.

26. Homyakov, D. M. and Homyakov, P. M. (1996). Fundamentals of system analysis. Moscow: Lomonosov Moscow State University.

27. Serdyutskaya, L. F. (2004). Multidimensional approach to the analysis of the model data taking as an example water objects. Hydrobiological Scientific Journal, 40(2), 104-112.

28. Unger, F. G. (1993). Regional ecological information modeling systems. Novosibirsk: Science.

29. Zaitsev, Yu. P., Polikarpov, G. G. (2002). Ecological processes in the critical areas of the Black Sea: synthesis of the results of two research dimensions from the middle of the XX to the beginning of XXI centuries. Marine Ecological Journal, 1(1), 33-55.

30. 2010 Environmental Performance Index. (2010). Yale: Yale Center for Environmental Law \& Policy.

31. HELCOM Initial Holistic Assessment. (2008). Ecosystem Health of the Baltic Sea in 2003-2007. In Baltic Sea Environment Proceedings, No. 122, (66 p.). Helsinki: Helsinki Commission.

32. Air Quality Annual Report. (2008). Riga: Latvian Environment, Geology and Meteorology Agency. Retrieved December 22, 2011, from http://www.meteo.lv/upload_file/GADA\%20PARSKATI/Parskats2008_both.pdf.

33. Latvian Ministry of Environment. (2009). Environmental Policy Strategy in 2009-2015. Riga: Informative section. 
34. Kuznetsov, S. I. (1970). Micro flora of the lakes and its geochemical activity. Moscow: Science.

35. Sergeyev, Yu. N. (1972). Problem of mathematical modeling of multicomponent physico-biological marine system. In Proceedings of Leningrad State University, Issue: Geology-geography, No 24, (pp. 114-125). Leningrad: Leningrad State University.

36. Eppley, W., Renger, E. U., Uenrick, E. L. (1973). A study of plankton dynamics and nutrient cycling in the central gyre of the North Pacific Ocean. Journal on Limnology and Oceanography, 18(4), 534-555. DOI: 10.4319/1o.1973.18.4.0534

37. Baltic Marine Environment Protection Commission: Helsinki Commission. (1986). In Baltic Sea Environment Proceedings, No 16, (176 p.). Helsinki: Helsinki Commission.

38. Baltic Marine Environment Protection Commission: Helsinki Commission. (1986). First Periodic assessment of the State of the Marine Environment of the Baltic Sea area, General Conclusions. In Baltic Sea Environment Proceedings, No 17A, (56 p.). Helsinki: Helsinki Commission.

39. Georgievsky, V. B. (1982). Identification and verification of the water ecosystem models. In Proceedings of the Conference 'Natural Waters Preservation, Protection and Quality Improvement Problems', (pp. 156-163). Moscow: Science.

40. Georgievsky, V. B. (1977). Identification and mathematical modeling of the eutrophication processes of the sea ecosystems: Journal "Ambio Special Report”, 5. Springer.

41. Hofbauer, J., Sigmund, K. (1988). The theory of Evolution and dynamical systems. London Mathematical Society, Cambridge: Cambridge University Press.

42. Bibikov, Yu. N. (1991). Guide book of the ordinary differential equations. Moscow: PhysMathLit.

43. Arnold, V. I. (1978). Additional chapters of the ordinary differential equations theory. Moscow: Science.

44. Yakubovich, V. A., Starshinsky, V. M. (1972). Linear differential equations with periodic coefficients and their applications. Moscow: Science.

45. Tikhonov, A. N., Samarsky, A. A. (2004). The mathematical physics equations. Moscow: Moscow State University Press.

46. Rimshans, J. S., Guseynov, Sh. E. (2007). Numerical Propagator Method Solutions for the Linear Parabolic Initial-Boundary Value Problems. Journal of Applied Mathematics and Mechanics, 7(2), 812-819.

47. Ieraga, I., Guseynov, Sh. E., Rimshans, J. S. (2011). Complementary slackness between the lowest terms coefficients of the 3D parabolic equation and the Newton boundary conditions constants. In Books of Abstracts of the International Conference on Scientific Computation and Differential Equations (SciCADE2011), Toronto, Canada, July 11-15, 2011 (p. 57). Toronto: the Fields Institute in Toronto.

48. Guseynov, Sh. E. (2012). Mathematical Models for Environmental Research and analyticonumerical methods of solving. Monograph. (324 + XII p.). West Conshohocken, Pennsylvania: The American Society for Testing and Materials (ASTM International). (In print)

49. Nedostup, L.M. (1982). Sensitivity of the water ecosystem models that are affected by the anthropogenic factor. In Proceedings "Natural Waters Preservation, Protection and Quality Improvement Problems", (pp. 139-155). Moscow: Science. 